\title{
Children's Rights in Children's Hearings: The Impact of COVID-19
}

\author{
Robert B. Porter ${ }^{a}$, Fern Gillon ${ }^{b}$, Fiona Mitchell ${ }^{c}$, Nina Vaswani ${ }^{\text {, }}$ \\ Emma Young ${ }^{e}$ \\ a) CELCIS, University of Strathclyde, Glasgow, Scotland, UK \\ Robert.porter@strath.ac.uk (correspondingauthor) \\ b) CYCJ, University of Strathclyde, Glasgow, Scotland, UK \\ fern.gillon@strath.ac.uk \\ c) CELCIS, University of Strathclyde, Glasgow, Scotland, UK \\ Fiona.mitchell@strath.ac.uk \\ d) CYCJ, University of Strathclyde, Glasgow, Scotland, UK \\ nina.vaswani@strath.ac.uk \\ e) CELCIS, University of Strathclyde, Glasgow, Scotland, UK \\ emma.young@strath.ac.uk
}

\begin{abstract}
The Scottish Children's Hearings System makes life-changing decisions regarding the care and protection of children up to 18 years of age referred due to a need for support because of offending behaviour or a risk to their physical or emotional safety. In March 2020, due to the COVID-19 crisis, Hearings underwent one of the most significant changes since their inception: proceedings shifted to an online conferencing platform ("virtual hearings"), and some procedural modifications were introduced. In June 2020 , we used an online survey to gather more than 270 responses from professionals, volunteers, young people, and families who had experience of virtual hearings. These responses highlight that while there are reasonable justifications for the use of virtual hearings, including the duty to ensure orders are appropriately reviewed and renewed, concerns related to children and young people's right to participation, privacy and representation bring into question the extent to which children's rights are realised in virtual Children's Hearings.
\end{abstract}




\section{Keywords}

participation - voice-children's hearings-welfare-decision-making-representation

\section{Introduction}

Compared to the rest of the UK and much of the world, Scotland has long taken a different approach to children who are in conflict with the law or in need of care and protection (Norrie, 2013). In 1968, the Social Work (Scotland) Act made provision for the structures outlined in the Kilbrandon Report (1964) for the creation of the Children's Hearings System. This was a system of panels which recognised that the behaviour of children was the result of their experiences and environment and aimed to address offending behaviour in the same way as instances that require care and protection, namely through the oversight of a panel of volunteers. Panels would engage all relevant parties in a discussion about the best way to promote the best interests, and to focus on the "needs not deeds", of the child.

There was little recognition of children's rights when the Kilbrandon Report was written, and as such the text of the report reflects perceptions of children's limited capacity for autonomous decision-making:

In the eyes of the civil law ... children are not regarded as completely free agents, and over a wide variety of fields of civil responsibility are debarred from rights of choice available to adults. Under the civil law a child in pupillarity [A child under the age of 14 (for boys) or 12 (for girls) who were regarded as under the "tutelage" of their parents] is held to be in a state of absolute incapacity. He has no "person" in the legal sense of the word, and is incapable of acting or even consenting (Kilbrandon Report, 1964, PARA. 67).

However, the processes and procedures laid out in the Kilbrandon Report provided for children and young people to enjoy many facets that we now firmly associate with children's rights.

The Hearings have a clear focus on the welfare of the child, achieved through a child-centred discussion among all relevant people, with space given to the child to express a view and have it taken into consideration. The extent to which this is a reality is the subject of some debate, with 
consultations with children and young people highlighting that hearings can be scary, challenges to having their voice heard, and a feeling that their views did not carry significant weight (Children's Parliament, 2010; Duncan, 2020; Kurlus et al., 2016; SCRA, 2016; Who Cares? Scotland, 2020). Hallett and Murray (1999) provided a comprehensive background to children's rights within Hearings and envisaged a number of changes required for their successful implementation.

Many of these changes have come to pass, in particular, the extension of funded legal representation (albeit subject to means testing and assessment of case complexity and ability of the applicant to participate in the absence of support) through the Scottish Legal Aid Board in 2013 (Porter et al., 2016, 2019), alongside the recent provision of advocacy services across Scotland following the Children's Hearings (Scotland) Act 2011. The 2011 Act brought in a range of changes to the Hearings System, aimed at modernising and standardising practice and processes, better to reflect children's rights and national standards. Some of the structural changes included the creation of the national Children's Hearings Scotland body tasked with recruiting, training and supporting panel members, and the establishment of a national panel of "safeguarders" (McDiarmid et al., 2017), who can be appointed when additional advice or support is required to safeguard the interests of the child in the proceedings (Hill, 200o). These were accompanied by various procedural and technical changes, including a clarification in Part 12 that the panel must ensure that the views of the child are accurately expressed. However, the basic tenets of the Hearings System remain unaltered.

For many years, the Hearings system has been criticised regarding the degree to which children's rights are upheld. Many children and young people have highlighted their dissatisfaction with Hearings, and the limitations that they experience to their participation (Children's Parliament, 2010; Kurlus et al., 2016; Who Cares? Scotland, 2020), while other research has challenged the extent to which children's views are truly heard and considered in decision making (Porter, 2020). However, in 2020, the Children's Hearings System experienced a challenge unlike any it had experienced before - the Coronavirus pandemic.

As a result of restrictions on movement and socialisation in the first "lockdown" within Scotland, face-to-face children's hearings were halted on 23 March 2020. There was an immediate pivot to "administrative" hearings, attended by panel members and reporters only through video conferencing (Children's Hearings Improvement Partnership, 2020). These were held in instances where orders were due to lapse, which would have left children and 
young people without their protection (Children's Hearings Scotland, 2020). On 7 April, the Scottish Government introduced the Coronavirus (Scotland) Act 2020, which made provisions to account for coronavirus within hearings. These changes included:

- Extending the validity of Compulsory Supervision Orders (Cso) by 6 months to a total of 18 months, and interim cso s by 22 days to 44 , in order to prevent orders lapsing.

- Removing a requirement for gender balance among panel members.

- Extending deadlines for submission of appeals.

- Allowing the electronic authentication of documents.

- Removing the obligation for a child to attend unless specifically directed by a Hearing.

- Allowing hearings to proceed with fewer than three panel members (with no lower limit imposed).

On 20 April 2020, testing of hearings supported by video conferencing (virtual hearings) were extended to children and young people, families and other professionals, with roll out to all hearings from 4 May 2020.

The use of virtual technologies has been the subject of examination in other contexts which are discussed here to inform our understanding of the challenges and benefits of such virtual engagement in legal contexts. However, before we move on to this discussion, it is important to highlight that while the impact of video evidence and participation in legal processes has been studied from the perspective of jurors (Krähenbühl, 2012) and decision makers (Rowden and Wallace, 2018), there is a lack of evidence regarding the experiences, needs, and perspectives of children and young people of virtual participation in legal processes. Given the specific and varying needs, roles and agency of children and young people in legal settings (Tisdall, 2016), it is highly likely that their perspectives on, and the associated benefits and challenges of, virtual technologies will differ to those of adults. With this caution in mind, we now turn to the limited literature on virtual participation.

Virtual participation of children and young people has been established within English criminal courts since 1999 through special measures. Hall (2009) explored the use of these special measures, which were designed to facilitate the provision of evidence from 'vulnerable and intimidated witnesses' (66). Hall challenges the benefits which are assumed to be afforded to children through these measures, highlighting that physical distance and virtual communication can be confusing, frustrating and intimidating for young people, stating that, "It is clear that the video link equipment itself will do little to keep 
young witnesses calm and (relatively) comfortable' (Hall, 2009: 79). Hall goes on to support the use of pre-recorded evidence, which allows a child or young person to share their views, experiences and wishes through a free narrative.

In April 2020, Byrom conducted a rapid review of evidence on the impact of remote hearings on access to justice worldwide. While the studies included were predominantly from an adult perspective, and were almost exclusively from either criminal or immigration removal proceedings, the five key findings all have relevance to the Children's Hearings setting: that parties do not fully appreciate the seriousness of proceedings conducted remotely; that part-video hearings impair the defendant's ability to communicate with their legal representatives; that technological issues make it more difficult to follow proceedings; that part-video hearings may negatively impact perceptions of credibility; and that remote hearings make vulnerability more difficult to identify and adjust for.

In addition to Byrom's review of the literature and in response to the Coronavirus pandemic there has been a greater focus on the experiences of virtual technologies. Research examining social work practice via virtual technologies highlighted a perceived reduction in relational social work, linked directly to the decrease in direct contact, particularly where there had not been a previous opportunity to develop a rapport with the service user (Turner, 2020a, 2020b). However, social workers have also raised positive elements related to workload management, such as a reduction in the time taken with travelling. Looking forward it is not clear how other management issues, such as addressing backlogs, may counteract these workload benefits, nor how they might impact on children's rights to participation and engagement.

In response to the pandemic, the Nuffield Family Justice Observatory conducted a rapid consultation with a range of stakeholders on the use of remote technologies within the English family justice system (Ryan et al., 2020a), which was then supplemented with a follow-up consultation (Ryan et al., 202ob). Both of these consultations relate to family court proceedings in England and Wales but their findings have clear parallels with work within the Scottish Children's Hearings context. Ryan et al. highlight challenges to participation through communication difficulties during hearings, the inability to be 'sufficiently empathetic, supportive, and attuned to lay parties' (Ryan et al., 2020b:1), and difficulties in providing appropriate support to those who were participating from their own homes, often alone, and with minimal support from legal representatives.

In the first consultation, the authors reported significant concerns about the fairness of remote hearings in some cases and circumstances. However, in the follow-up consultation, professionals were reported to be satisfied with the 
fairness of the proceedings, but noted a concern about whether they were perceived as such by families. Technological challenges were reported to be ongoing through both consultations, with reports of difficulties accessing hearings due to a lack of hardware, connectivity or skills, and papers not reaching all those entitled to them, including lay parties and the judge or bench. Across the consultations, the majority of experience is in relation to adults or their perceptions of children's experiences - which may differ due to the greater level of support required by children fully to participate in proceedings.

Against this background a rapid review of experiences of virtual children's hearings was completed to understand how virtual hearings impacted upon the hearings process, the extent to which experiences in other settings were reflected in this unique context, and to produce information to support the development and improvement of the hearing experience.

\section{2}

\section{Methodology}

In partnership with the Scottish Children's Reporter Administration (SCRA) and Children's Hearings Scotland (CHS), an online survey was developed to capture the views and experiences of those who had participated, or wished to have participated, in virtual hearings. The questions were primarily qualitative in order to capture as much detail and contextual information about individuals' experiences as possible. The responses were analysed by individual researchers according to participants "role" within the hearing. The team then came together to analyse thematically the results across the groups, and clarify the findings.

The questions were devised primarily to address experiences of virtual hearings (i.e. those hearings which had taken place using video conferencing software for all parties). However, on 21 May 2020, the First Minister for Scotland announced plans for face-to-face Hearings to be resumed, incorporating social distancing measures. Accordingly, questions were adjusted to ensure the experiences of those who might have experienced such socially distanced hearings were gathered.

Responses were sought from children, young people $(12+)$ and adults. Due to the ethical and methodological considerations which must be made for conducting research with younger children, the rapid nature of this study, and social restrictions at the time, under 12s were not eligible to take part in the survey. The primary ethical issues which remained were around preventing distress and upset for respondents, and informed consent. To address these, potential participants were provided with comprehensive information about 
the study and the future use of any information they might provide, as well as directions to a range of online-resources for information and emotional support. Ethical approval for the study was obtained from the University of Strathclyde Ethics Board, and data was collected for two weeks from 15 to 28 of June 2020.

Participants were recruited through a range of avenues, including via institutional networks, partner organisation networks, and via promotion through social media channels of institutions and individuals involved in the research. We encouraged the wider dispersal of the invitation by those with an interest in the research or the Hearings more generally.

In total, 418 responses to the survey were received from children and adults. Initial data preparation resulted in the removal of 142 responses who had not answered any of the qualitative questions, as this made it impossible to reflect their views and experiences. This resulted in 276 included responses, which came from a variety of roles within the Hearings system as shown in Table 1.

TABLE 1 Respondent Roles

$\begin{array}{lll}\text { Respondent Role } & \begin{array}{c}\text { Direct Experience } \\ \text { of virtual hearings }\end{array} & \begin{array}{c}\text { No direct experience } \\ \text { of virtual hearings }\end{array}\end{array}$

\begin{tabular}{lrcr}
\hline $\begin{array}{l}\text { Young people (aged 12 } \\
\text { or above) }\end{array}$ & 2 & 3 & 5 \\
Parents & 0 & 4 & 4 \\
Other family members & 4 & 0 & 4 \\
Kinship carers & 0 & 0 & 0 \\
\hline Foster carers & 6 & 0 & 6 \\
Residential carers & 1 & 1 & 2 \\
Panel members & 136 & 9 & 145 \\
Reporters & 11 & 0 & 11 \\
Social workers & 32 & 5 & 37 \\
Safeguarders & 14 & 2 & 16 \\
Advocacy workers & 11 & 0 & 11 \\
Solicitors & 20 & 0 & 20 \\
\hline Other & 9 & 6 & 15 \\
\hline Total & $\mathbf{2 5 0}$ & $\mathbf{2 6}$ & $\mathbf{2 7 6}$ \\
\hline
\end{tabular}


The use of an online survey is likely to have impacted upon the responses from different groups, especially in the context of digital poverty (see discussion in 4.2.1.3 below). Despite efforts to promote and circulate the research among young people aged $12+$ and families, we received relatively few responses from these groups. This regrettably continues the trend of research which is unable to reflect accurately and consider the experiences of children and young people of virtual participation. Alternative methods of data collection (such as interviews or focus groups) would likely improve participation among these groups, but were not possible in the timeframe and context in which the research took place. Conversely, approximately 50 per cent of responses were from panel members, and over 85 per cent were from professionals involved in the system. This naturally skews responses towards professionals' perceptions of what is appropriate, proportionate, achievable and desirable in the context of virtual participation.

Although no face-to-face hearings with social distancing measures are reported by SCRA to have taken place prior to or within the data collection period, two respondents indicated that they had taken part in such a hearing in addition to virtual hearings, it is possible that this was in reference to a pre-hearing panel or other meeting. Given that no face-to-face hearings with social distancing took place, these portions of the response have not been included in the analysis.

\section{Discussion of Rights Issues in Virtual Hearings}

While the data presented relates to the Children's Hearings System, the rights issues raised reflect important considerations for all virtual hearing processes worldwide. As in other contexts, the move to virtual hearings as a response to the coronavirus pandemic was conducted quickly and responsively, with an initial trial period for testing and problem solving. Clearly, all organisations and individuals concerned were working hard to address the challenges the move online brought. Since the consultation on which this paper is based was conducted, additional improvements have occurred such as distribution of hardware to some families and a greater familiarisation with video conferencing technologies (Getting People Online, 2020). However, the difficulties which are outlined and discussed below represent an ongoing challenge to the full realisation of children's rights within all virtual hearings. Through clarifying these challenges, we hope to stimulate further discussion of possible solutions. 
Despite the varied backgrounds and roles of the groups of respondents, there was perhaps a surprising degree of similarity in their views and experiences of virtual hearings. The majority of respondents (go per cent) had direct experience of virtual hearings, while 10 per cent provided opinions or views not based on direct experience (as they may not have been able to join a virtual hearing, for example).

\subsection{Child, Carer and Parent Views}

Five young people completed the survey, a low number which limits the extent to which we can contribute to understanding children and young people's direct experience of virtual participation. However, the experiences that were shared reported mixed support, which was seen to impact on their positive participation in their virtual hearing. The young people who had direct experience found the experience confusing and difficult, and reiterated the need to prioritise support for young people to enable them to feel prepared and take part:

I felt a bit under pressure as I struggle with anxiety and I didn't have the opportunity to ask to speak the panel by myself as my mum and everyone was on the screen. My Social Worker and I had a signal for when I needed her to speak for me but I still felt that I was asked to share my views and be part of discussions that I would usually have been protected from ... (YOUNG PERSON).

Parents and carers, 16 respondents in total, while identifying some positive aspects of virtual hearings, overall reported they were impersonal and, aside from the public health aspect, were not an acceptable medium for a hearing:

... These panels are vitally important to ensure the safety and well-being of children ... and should be conducted correctly in the hearing room where all points can be made and responded to fairly. It was impossible to do this using this flawed video system which led to a ridiculous decision being made. This was a mockery of the hearings that I have previously attended which have all been in person and run fairly to all ... (FAMILY MEMBER).

While most did receive support prior to and during taking part, they felt it was not a suitable way for children and young people to meaningfully and positively take part. 


\section{2}

\section{Rights Issues for Virtual Hearings}

3.2.1

Article 12 United Nations Convention on the Rights of the Child (UNCRC): Right to Voice and Participation

Article 12 as it is expressed in the UNCRC and interpreted in the General Comment on Article 12, clearly articulates the right a child or young person has to take an active role in decisions which affect their life, and it is hard to imagine circumstances in which this applies more clearly than in the decisions made by Children's Hearings. The General Comment on Article 12 highlights the emergence of "participation" as a conceptualisation of processes which work to fulfil rights under Article 12. The Hearing processes reflect this through: the requirement for a child to attend their own hearing; the opportunities afforded children to provide their views in a range of different mediums; and the training which is given to panel members before they are certified to sit on Hearings.

Article 12 rights and participation were significantly impacted in virtual Hearings through a variety of mechanisms, discussed in the following subsections. Taken individually, and particularly in combination, the complexities of virtual participation particularly for children, young people and families suggest significant barriers to the full realisation of the right to voice and participation in a decision-making process which has far reaching consequences.

\subsubsection{Attendance}

As previously noted, the 2020 Act removed the requirement for a child to attend their hearing unless specifically excused, and this appears to have had a large impact, with respondents noting a significant (albeit anecdotal) reduction in the number of children attending their Hearing. The reasons suggested for this are varied and included refusing to attend, the removal of the compulsion to attend, a lack of support to attend, and being excused from needing to attend.

It is clear that a reduction in attendance carries with it a reduction in the ability of children and young people to take an active part in a hearing, and to enjoy their Article 12 rights. However, we must be mindful that a child's non-attendance may also be a way of communicating a view regarding the process that we have a duty to acknowledge and understand. Children, young people and carers gave examples of instances where they attended hearings but did not feel able to take part fully. Reasons for this included limitations related to hardware, software and connectivity, as well as challenges related to the virtual medium (discussed below). 


\subsubsection{Support}

The main concern in fulfilling Article 12 rights for professional participants was the support available to children, young people and families, prior to, during and after the hearing. Children's reporters and social workers raised concern about the lack of emotional support available to prepare participants and support them during and after a decision has been made:

As a panel member, making the decision to remove a child from their parents immediately, and the family having to cope with hearing that without support (PANEL MEMBER).

This is a particular concern where difficult decisions are to be made about where a child or young person resides, whether they should be deprived of their liberty, or issues such as contact. Attending and participating in hearings can be anxiety inducing, uncomfortable and potentially (re)traumatising for children and young people due to the subject matter discussed, the participants who may be present, as well as the format it takes and the decisions which can be made. Emotional support can facilitate participation in ways which ensure the child is comfortable and confident in sharing their views and experiences, and subsequently in order for them to understand, if not to accept, the process and decisions made.

\subsubsection{Technology}

Significant technological concerns were raised as a primary barrier to participation, including access to adequate equipment, software and internet, particularly but not exclusively for children, young people and families. In its comments on non-discrimination, General Comment No. 25 (2021) on children's rights in relation to the digital environment highlights that the right to non-discrimination, 'requires that States parties ensure that all children have equal and effective access to the digital environment' (2021: 2, para. 9). In addition, participant's competence and confidence in using technology can limit full and active participation beyond simply accessing the virtual hearing:

The mother did not have access to the internet, so I had to go to her house and let her take part on my mobile. The mobile phone was very small for two people, but because she does not have wifi, I could not use my laptop. Her own mobile phone was unable to download the app. This was not ideal for two reasons: using the mobile was hard for us both and every time I tried to mute us and unmute us, we got disconnected (SOCIAL WORKER). 
Technical difficulties were frequently noted as having a highly detrimental and disruptive impact on hearings, could leave participants feeling frustrated, fuelling disengagement and feelings of disempowerment:

The whole hearing was a chaotic jumble with very little direction, most of the important relevant points were unable to be discussed or dealt with ... These panels are vitally important to ensure the safety and well-being of children .... and should be conducted correctly in the hearing room where all points can be made and responded to fairly. It was impossible to do this using this flawed video system which led to a ridiculous decision being made (FAMILY MEMBER).

\subsubsection{Formality}

Participants noted an increase in formality and "turn taking" in the conduct of hearings. This is more challenging to interpret, with some participants indicating that it improved the process and focus of the Hearing. The "feel" of the hearing was noted as more formal, procedural and directive. However, some respondents noted this as a positive aspect of the move to virtual hearings, stating they were less confrontational and more focused. However, it also runs the risk of limiting the 'full and open discussion' which is the aim and purpose of a Hearing.

The importance of a skilled and confident Hearing Chair was reiterated and seen as integral to the proceedings of a virtual hearing being inclusive and fair:

As a chairing panel member it is far more difficult to manage and ensure hearing is fully inclusive (PANEL MEMBER).

The more considered approach to virtual hearings required to ensure everyone, particularly children, young people and families, had the opportunity to participate meant that virtual hearings could last longer than face-to-face hearings. This has a disproportionate impact on the participation of some groups (younger children, participants with learning disabilities etc.):

Inevitably, discussions take longer and require a level of concentration which is different from a normal hearing, not least as you feel 'detached' to a degree lots of the time! (SAFEGUARDER).

The increased formality may also disproportionately impact upon the participation of children and young people (and families), who are less familiar with the process and opportunities for participation: 
I'm extremely aware that many children and young people struggle to communicate via technology. Many of my case load will only engage in the face to-face in-person way. This makes it challenging to ensure their voices are truly being heard and represented in decision making (ADVOCACY WORKER).

This perception clearly runs counter to the popular categorisation of young people as 'digital natives' (Prensky, 2001a, 2001b). However, the presumption that youth or generational belonging is, on its own, sufficient to confer digital fluency is one which is challenged as too simplistic (Bennett et al., 2008), with suggestions that digital fluency is over-estimated in young people (Helsper and Eynon, 2010). It is also important to note that digital fluency relates to the ability to navigate, integrate, use and produce information presented in digital settings, however the content and presentation of information within virtual hearings remains firmly in the analogue world. In particular, the child or young person has no ability to interact with the information as they might with a video (e.g navigating the information in a non-chronological manner).

Generally, it may be noted that virtual hearings predominantly represent an attempt to recreate face-to-face communication, rather than an attempt to embrace digital methods of communication. General Comment No. 25 (2021) on children's rights in relation to the digital environment appears to acknowledge this to some extent in recognising the challenges in digitisation of 'court proceedings' and states that, 'States parties should provide in-person contact to facilitate children's ability to meaningfully engage with the courts and their rehabilitation' (2021: 25, para. 120).

\subsubsection{Non-verbal Communication}

The challenge of not being able to see facial reactions or body language was highlighted by adult respondents. This has great importance when considered in relation to the participation of the child. Children may convey a significant amount of information, and thus participate in the decision making, through body-language and reaction. In situations where they are not comfortable speaking, children may impart specific information, such as (dis)agreement with statements, through to more contextual and general information, such as that they are uncomfortable talking about (or listening to discussions of) a topic, that they wish to speak, or that they are (dis)engaged from the process as a whole (Jones, 2003):

Missing being able to see their reactions to discussions means we may miss important clues as to what is really going on with their lives (PANEL MEMBER). 
In face-to-face hearings, such information would be picked up by decision makers and used in the course of the Hearing, either to provide an opportunity to speak, enquire further of the child's opinion or view, or to alter the tone, content or method by which the Hearing is proceeding. Respondents indicate that in virtual hearings this information is lost, removing a method through which children might realise their Article 12 rights, excluding the information from the decision-making process, and reducing the opportunities for children and young people to play a lead role in decisions about their lives.

\subsubsection{Adequacy of the Home Environment}

Some respondents reported reservations about the extent to which the home environment facilitated the participation of the child or young person. They highlighted the distractions that can occur within a home which might detract from a child's attention to the Hearing. Others noted that attending a hearing in a familiar home environment could be more relaxing for the child, promoting positive experiences and engagement, and did not incur the disruption and anxiety of travel. It was also noted that children may benefit from not being face-to-face with individuals at whose hands they may have experienced physical or emotional trauma.

\subsubsection{Article 8 ECHR, Article 16 UNCRC: Privacy}

Article 8 of the European Convention on Human Rights outlines the right to a private family life, and under Article 16 of the UNCRC has protection from arbitrary or unlawful interference with his or her privacy, family, home or correspondence. Hearings frequently discuss topics which are extremely sensitive to the child and others, and relate to highly personal information. Accordingly, the information provided to Hearings is confidential; however, such confidentiality is extremely hard to manage within a virtual hearing. Under the practices which are explored in this paper, the home environment may also impact upon privacy concerns within virtual Hearings, and privacy is an issue of great concern for children and young people (Who Cares? Scotland, 2020). Having many participants in home or other shared locations presents a significant risk of breaches. Hearings frequently hear information which is known or accessible only to certain individuals, and while we would expect panel members, reporters and others in Hearings to take appropriate steps, there remains a significant risk of information presented at hearings being accidentally or deliberately overheard by others (such as siblings) within the home. This is supported by respondent reports of other individuals being in the room with hearing participants during virtual hearings: 
If [a] child is at home he/she will probably be literally sharing a device with parent for the purpose of participating. Requesting to speak to panel on their own could be challenging ... (SAFEGUARDER).

Given the sensitivity of information discussed in hearings, such breaches of the right to private life will always have impacts on the children and young people concerned, but in the contest of a virtual hearing could have additional and significant implications for the safety of participants:

Additional risks to children who remain at home with parents/carers while decisions are being made that may be distressing to the young person or family, whereas in face-to-face hearings there was an additional layer of safety (SOCIAL WORKER).

\subsubsection{Article 8 European Convention on Human Rights (ECHR): Representation in Virtual Hearings}

Children's Hearings are legal forums in which decisions are made with far-reaching consequences for the lives of children, young people and families. Measures contained in a cso have consequences which can include an enforced change of residence, restrictions or elimination of contact with individuals, and the creation of a criminal record. Due to the significance of these decisions, there are provisions to allow the direct representation of children and young people by solicitors, advocacy workers and/or safeguarders. Similar powers and provisions are available within welfare courts or decision-making bodies worldwide which are now using virtual platforms.

Article 8 ECHR takes the view that private correspondence with lawyers falls within the scope of "private life" as the purpose of the relationship is to allow an individual to make informed decisions about his or her life. Previous research has highlighted the role that solicitors (Porter et al., 2019) and safeguarders (McDiarmid et al., 2017) have to play in the conduct of a hearing. Of particular relevance is the value of the solicitor role in preparing clients for hearings (in terms of what will happen and potential outcomes), presenting or supporting their client to present, views and wishes, and in ensuring their client's understanding of the hearing as it progresses. These are all areas where solicitors, advocacy workers and safeguarders indicated that their role was compromised within virtual hearings:

as a solicitor it is very difficult to assist the client personally and you cannot provide the service that you can provide when you are able to sit next 
to the client for many people they are not comfortable on the screen for children it is not what they want to do (SOLICITOR).

Specific concerns were raised about the lack of "breakout" spaces for children to communicate privately with panel members, legal counsel, advocacy or support.

The impacts of this are hard to quantify, but it is clear that virtual environments as they currently operate significantly restrict the ability of these professionals to appropriately support children's understanding of the processes or decisions. This is likely to result in a lack of understanding around what has happened, why decisions have been made, or how children and young people could best participate in Hearings.

3.2 .4

Article 6 ECHR, Article 13 UNCRC: Right to a Fair Trial, and Access to Information

Children have the right to freedom of expression; including freedom to seek, receive and impart information and ideas of all kinds ... either orally, in writing or in print, in the form of art, or through any other media of the child's choice' (Article 13, UNCRC). A key mechanism through which children, young people and families can understand and participate in the decision-making process is through understanding the information on which that decision is based. In Children's Hearings, as with most decision-making bodies, reports are normally distributed in paper copy to all relevant persons, the child or young person (if over the age of 12), and/or any legal representatives of the child or relevant persons. In the move to virtual hearings, and to address practical challenges to the distribution of paper copies, hearing papers were uploaded to an online repository (Objective Connect), and access was granted to all eligible individuals.

The requirement to access paperwork digitally required participants to move between two software packages. Not only did this restrict access to papers for some participants such as panel members, it could also disrupt the flow of the hearing:

Papers are difficult to use and IT solutions are not inclusive (PANEL MEMBER).

Respondents highlighted challenges in accessing and using this information system, and in consulting and referencing papers during Hearings. Solicitors also reported difficulty in accessing papers, meaning that they were unable to gain an appropriate understanding of the situation in order to advise their 
client. Once again, this difficulty limits both the representation of children and young people, and their opportunity to participate meaningfully in the decisions about their lives.

Finally, the connectivity issues identified by participants, as well as the challenges accessing paperwork through online systems, highlight the difficulties that panel members may have in obtaining all relevant information. Whether their connections prevent them hearing information from participants, or they are unable appropriately to review the paperwork, this represents incomplete information on which significant decisions in children's lives are being made. A small number of respondents specifically highlighted concerns related to the cumulative complexities of virtual hearings, and this issue in particular, lead to concerns about due process and procedural fairness:

As a solicitor, in terms of article 6 rights [ECHR article 6: right to a fair trial] - my client has the right to be able to follow and understand proceedings which in turn means having a direct line of communication with the client. This is difficult if I am not in the same room as them (SOLICITOR).

\subsection{Looking Forward}

3.3.1 Long-Term Impact of Covid-19 Response

The Children's Hearings System's response to the coronavirus has an ongoing impact for children, which will, and was always very likely to, continue beyond the length of lockdown measures. Due to the reduced capacity of the system during the COVID-19 response, there is a significant volume of Hearings which need to take place in the coming 12 months. One of the implications of this is that there is minimal chance of a child who had a cso extended through an "administrative" hearing in March or April of 2020 having a further Hearing until after March or April 2021, with a high likelihood (given the number of hearings to be held) of the cso lasting more than the anticipated 12 months, up to the extended maximum of 18 months. In total, this means that there are children on csos who are subject to state intervention in their lives, who may not have an opportunity to participate in the process of decision making for a period of up to two and a half years. In addition to stretching compliance with Article 25 UNCRC to a 'periodic review', when this opportunity is presented, it is likely that the challenges outlined in this paper will, to some extent, remain.

3.3.2 A Future of "Blended Hearings"?

Aswith other evaluations of online participation, particularlydueto COVID-19 restrictions (Byrom, 2020; Ryan et al., 2020a; Turner, 2020b), there are 
suggestions that for some young people there are positive aspects to attending their hearing online. Arguably, for some children and young people, virtual attendance and participation at a hearing would be preferable to attending face-to-face. Support services, socialising and education have all moved online to greater or lesser extents during the pandemic, increasing familiarisation with online engagement, and practical aspects of virtual participation such as being able to turn off their camera may empower young people.

However, we have outlined many complexities with virtual hearings which suggest they do not adequately support children and young people's meaningful participation and uphold their rights. To suggest that these challenges are unique to virtual hearings may not be accurate. Similar issues are raised in relation to face-to-face hearings, including: problems understanding the information given prior to, during and after a hearing (Kurlus et al., 2016); that it is an adult, rather than a child-centred process (Children's Parliament, 2010), and that hearings are unable to listen effectively and engage with children while making complex decisions (Duncan, 2020). Shamefully, some young people have indicated that they would actually prefer to be dealt with by the courts, than children's hearings (Vaswani and Gillon, 2018). Further research with children and young people is essential to ensuring that any changes to the system are "child-friendly", strengthen participation and empower younger participants. We are approaching a future where "blended hearings", giving children, young people and families the option to participate either virtually or face-to-face, becomes standardised within the Hearings system. In consideration of the evidence presented here we have concerns that this option will not sufficiently address issues in relation to participation and the promotion of children's rights.

\section{Conclusion: are Virtual Hearings "Justified"?}

The move to virtual hearings in tribunals around the world was rapid and necessary in the circumstances of the CoviD-19 pandemic in 2020. The data and discussion in this paper has highlighted challenges to the realisation of children's right in virtual hearings which beg the question: are virtual hearings justified? Despite the complexities and concerns raised by respondents, and their implications for the rights of children, when asked if virtual hearings were justified in light of the "lockdown", over 9o per cent of respondents in our consultation said that they were. Although not articulated as such, justifications related to UNCRC Articles 9, 19, and in particular Article 25, highlighting the 
importance of hearings in protecting children from harm, maintaining legal protections and regularly reviewing placements.

However, in light of the challenges explored in section 4.2, and the long-term implications discussed in 4.3, it is not clear for how long this will remain the case. Difficulties related to participation, representation and understanding of the process demonstrate challenges to the core principles of procedural and interpersonal justice. These core principles are cornerstones of a just process, and limitations upon them run the risk of generating unfair processes and outcomes. As systems and individuals become increasingly accustomed to virtual engagement, and the idea of incorporating virtual technologies into legal and quasi-legal processes gains momentum, these issues can only become more pronounced. Going forward, the credibility of virtual decision-making environments as rights respecting will depend upon embracing and realising these fundamentals within a digital context.

\section{References}

Bennett, S., Maton, K. and Kervin, L., “The 'digital natives' debate: A critical review of the evidence", British Journal of Educational Technology 2008 (39(5)), 775-786. Doi.org/10.1111/j.1467-8535.2007.00793.x.

Byrom, N., What we know about the impact of remote hearings on access to justice: $A$ rapid evidence review, Nuffield Family Justice Observatory (2020): https://www. nuffieldfjo.org.uk/app/nuffield/files-module/local/documents/nfjo_remote_ hearings_vulnerable\%2ogroups_rapid\%2oreview_20200506.pdf.

Children's Hearings Improvement Partnership, Children's Hearings System-Update Monday 20 April 2020, Children's Hearings Improvement Partnership: https://www. chip-partnership.co.uk/wp-content/uploads/2020/o4/Childrens-Hearings-updateMonday-2o-April-2020.pdf.

Children's Hearings Scotland, Participation in virtual children's hearings during the Coronavirus [Text/html]. Children's Hearing Scotland April 20 2020): https:// childrenspanelscotland.org/about-us/latest-news/participation-in-virtualchildren-s-hearings-during-the-coronavirus/.

Children's Parliament, Children's Hearings Reform: The Views of Children. Children's Parliament (2010): https://www.childrensparliament.org.uk/wp-content/uploads/ Childrens-Hearings-Reform-Report.pdf.

Duncan, F., The Independent Care Review: The Promise (2020): https://www.carereview. scot/wp-content/uploads/2020/o2/The-Promise.pdf.

Getting people online, Scottish Government News (2O2O): https:/www.gov.scot/news/ getting-people-online/. 
Hall, M., Children Giving Evidence through Special Measures in the Criminal Courts: ProgressandProblems, ChildandFamilyLawQuarterly20o9(21),65:https://heinonline. org/HOL/Page?handle=hein.journals/chilflq21\&id=65\&div=\&collection=.

Hallett, C. and Murray, C., “Children's Rights and the Scottish Children's Hearings System", International Journal of Children's Rights 1999 (7), 31-52.

Helsper, E. J. and Eynon, R., "Digital natives: Where is the evidence?", British Educational Research Journal 2010 36(3), 503-520. Doi.org/10.1080/01411920902989227.

Hill, M., The Role of Safeguarders in Scotland, (2000) Scottish Executive 117.

Jones, D., Communicating with vulnerable children: A guide for practitioners (Gaskell, 2003).

Kilbrandon Report, Children and Young Persons Scotland: Report by the Committee Appointed by the Secretary of State for Scotland (HMSO, 1964).

Krähenbühl, S., “Does the jury really need to hear it all?': The effect of evidence presentation practice on jury assessment of children's eyewitness testimony", Psychology, Crime \& Law 2012 (18(9)), 847-858. Doi.org/10.1080/10683 16X.2011.579904.

Kurlus, I., Henderson, G. and Brechin, G., The Next Steps Towards Better Hearings. Scottish Children's Reporter Administration (2016): http://www.chip-partnership. co.uk/wp-content/uploads/2016/10/Better-Hearings-Research-Report-2016.pdf.

McDiarmid, C., Barry, M., Donnelly, M. and Corson, S., The Role of the Safeguarder in the Children's Hearing System (Social Research Series, 2017), The Scottish Government: http://www.gov.scot/Resource/oo52/00526444.pdf

Norrie, K. M., Children's Hearings in Scotland (Green, 2013).

Porter, R. B., "Recording of Children and Young People's Views in Contact DecisionMaking", The British Journal of Social Work 2020 (50(6)), 1796-1815. Doi.org/10.1093/ bjsw/bcz115.

Porter, R. B., Welch, V. and Mitchell, F., The Role of the Solicitor in the Children's Hearings System, CELCIS (2016): https://www.celcis.org/files/8514/7576/7298/CELCIS-The_ role_of_the_solicitor_in_the_Childrens_Hearing_System_-_2016.pdf.

Porter, R. B., Welch, V. and Mitchell, F., (2019). "Adversarialism in informal, collaborative, and 'soft' inquisitorial settings: Lawyer roles in child welfare legal environments", Journal of Social Welfare and Family Law 2019 (o(o)), 1-20. Doi.org/10.1080/o9649o 69.2019.1663015.

Prensky, M., (2001a). "Digital Natives, Digital Immigrants Part 1", On the Horizon $2001 \mathrm{a}$ (9(5)), 1-6. Doi.org/10.1108/10748120110424816.

Prensky, M., (2001b). “Digital Natives, Digital Immigrants Part 2: Do They Really Think Differently?", On the Horizon 2001b (9(6)), 1-6. Doi.org/10.1108/10748120110424843.

Rowden, E. and Wallace, A., (2018). "Remote judging: The impact of video links on the image and the role of the judge", International Journal of Law in Context 2018 (14(4)), 504-524. Doi.org/10.1017/S17445523180oo216. 
Ryan, M., Harker, L. and Rothera, S., Remote hearings in the family justice system: A rapid consultation (2O2Oa), Nuffield Family Justice Observatory: https://www.nuffieldfjo. org.uk/app/nuffield/files-module/local/documents/remote-hearings-rapid-review. pdf.

Ryan, M., Harker, L. and Rothera, S., Remote Hearings in the family justice system: Reflections and experiences. Follow-up consultation (2020b), 66. Nuffield Family Justice Observatory.

SCRA, National Survey of Children and Families, Scottish Children's Reporter Administration (2016).

Tisdall, E. K. M., "Subjects with agency? Children's participation in family law proceedings", Journal of Social Welfare and Family Law 2016 (38(4)), 362-379. Doi.org/10.108o/og649069.2016.1239345.

Turner, A., "Coronavirus has negatively impacted practice, social workers say", Community Care (28 May 2020a): https://www.communitycare.co.uk/2020/05/28/ social-workers-say-coronavirus-negatively-affected-services-people-they-support/.

Turner, A., "Social workers' perspectives on practice under lockdown", Community Care (2 June 2020b): https://www.communitycare.co.uk/2020/06/o3/socialworkers-perspectives-practice-coronavirus-lockdown/.

United Nations General Comment No. 25 on Children's rights in relation to the digital environment (2021), 20.

Vaswani, N. and Gillon, F., CYCJ Stakeholder Consultation (2018), 9.

Who Cares? Scotland, Young people \& parents'views on privacy and how this affects their participation in the Children's Hearings System. Who Cares? Scotland (2020). 